\title{
NARRATIVAS PARAENSES E EUROPEIAS NA AMAZÔNIA - IDENTIDADES, MEMÓRIAS E JOGOS DE PODER
}

\author{
Haline Fernanda Silva MELO \\ Helder Fabricio Brito RIBEIRO ${ }^{2}$ \\ Hellen Cristina Aleixo Azeredo MOURA ${ }^{3}$
}

\begin{abstract}
RESUMO
Atualmente, os Estudos de Literatura têm procurado aproximar o diálogo crítico e epistemológico entre Literatura e as mais diferentes áreas do conhecimento humano. Tal fato já se tornou, inclusive, uma das premissas da Literatura Comparada, que há muito deixou de fazer análises simplesmente binárias entre as diferentes literaturas (autor- autor; personagem-personagem, etc.). Sob esta perspectiva, este trabalho propõe intersectar os trânsitos e recortes culturais existentes entre a literatura colonizadora europeia e as narrativas amazônicas para projetar marcas e marcos que venham a compor a cultura amazônida nortista híbrida, tendo como objetos de estudo a literatura, a língua e algumas imagens da arquitetura de Belém. A língua, neste estudo, deve ser entendida como entidade social em constante transformação por nós que a inventamos e reinventamos todos os dias, sendo uma das principais manifestações da nossa brasilidade, formada por inúmeros sotaques e expressões. Na proposta deste artigo, faremos uma breve análise comparatista dos jogos de poder presentes em alguns topônimos da Amazônia, através das narrativas paraenses e europeias, entendendo que a primeira se relaciona com a indígena e a segunda com as espanholas e as portuguesas. O termo narrativa foi escolhido por seu valor polissêmico. Nesta ótica de narrativa, entendida como expressão de histórias, sendo elas europeias ou dos nativos- os índios; trataremos neste estudo comparatista apoiando-nos nos gêneros crônica de viagem e mito. A metodologia desta pesquisa tem uma abordagem qualitativa e um cunho bibliográfico. Para tanto, este estudo, articula-se entre as categorias "Ensino de Literatura" - Regina Zilberman, "Literatura Comparada" - Carvalhal (1994); "Identidade" - Maldonato (2005), Tupiassu (2000) dentre outros.
\end{abstract}

Palavras-chave: Sujeitos. Identidades. Representações Sociais.

\begin{abstract}
Currently, Literature Studies have sought to bring the critical and epistemological dialogue between Literature and the most different areas of human knowledge. This fact has already become the main premise of Comparative Literature, which has long since failed to make analyzes that are simply binary between different literatures (author-author, character-character, etc.). From this perspective, this work proposes to intersect the cultural transits and cultural cuttings existing between the European colonizing literature and the Amazonian narratives to design brands and landmarks that come to compose the hybrid North American Amazonian culture, having as objects of study the literature and the language. The language in this study must be understood as a social entity in constant transformation by us that we invent and reinvent every day, being one of the main manifestations of our Brazilianness, formed by innumerable accents and expressions. In the proposal of this article, let's take a brief comparative analysis of the power games present in some Amazonian toponyms through the para- and European narratives, understanding that the first relates to the indigenous and the second to the Spanish and Portuguese. The term narrative was chosen for its polysemic value. In this perspective of narrative, understood as expression of stories, being they European or of the natives, the Indians, we will treat this comparative study supporting us in the chronic genres of travel and myth. The me1 Doutoranda do Programa 2 Doutorando do Progra- de Pós-Graduação em Code Pós-Graduação em Comu- ma de Pós-Graduação em municação, Linguagens e nicação, Linguagens e Cultura Comunicação, Linguagens Cultura-PPGCLC/UNAMA. - PPGClC/UNAMA. Turma e Cultura - PPGCLC/UNA- Turma 2016.2. E-mail: helle2016.2. E-mail: halinefernan- MA. Turma 2016.2. E-mail: da23@gmail.com.
\end{abstract}
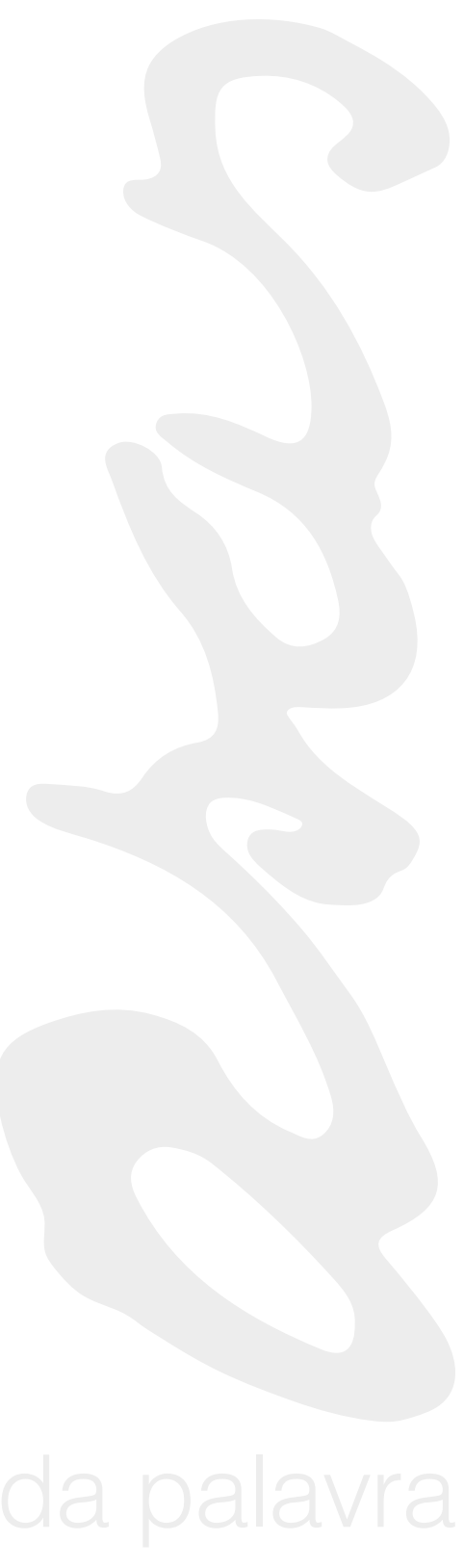

VOL. 14 | N. 1 | JUN. 2017 com.br. 
thodology of this research has a qualitative and bibliographical approach. For this, this study is articulated between the categories "Teaching Literature" - Regina Zilberman, "Comparative Literature" - Carvalhal (1994); "Identity" - Maldonato (2005), Tupiassu (2000); among others

Keywords: Subjects. Identities. Social Representations.

\section{INTRODUÇ̃̃O}

A Região Norte do Brasil contém um rico imaginário popular, o qual contém um conjunto específico de símbolos, rituais, mitos e crenças que, em geral, consiste no entendimento que as pessoas de uma comunidade ou grupo incorporam sobre os mistérios e o incomum no cotidiano. Nesse artigo, procuraremos discutir as relações de poder que permeiam as nomeações de coisas e personagens do nosso imaginário amazônida-nortista.

Por conseguinte, selecionamos como objetos de estudo as crônicas de viagem do frei Carvajal, algumas mitologias indígenas e imagens da Belém. O viés teórico adotado neste trabalho inclui Barthes (2005), Durand (1999), Foucault (2004), Koch e Bentes (2000), Maldonato (2005), Moscovici (2011), Tupiassu (2000).

\section{RELAÇÕES DE PODER DA LÍNGUA E/OU UM BREVE HISTÓRICO ORIGEM DA LÍNGUA PORTUGUESA}

Desde os tempos mais longínquos a língua representou uma forma de poder do dominante para com o dominado. Tomemos como exemplo a origem da língua de nosso "conquistador", a língua portuguesa, que possui em sua gênese o Latim vulgar que advém do Latim Clássico.

S egundo Lima (2008), o português pertence ao grupo de Línguas Românicas. A formação România deve ser considerada como sinônimo do percurso histórico do Império Romano e da língua latina, desde sua expansão territorial, por intermédio de guerras, até a dissolução e queda do Império. Deste modo, pode-se ressaltar que as conquistas do Império Romano contribuíram para a divulgação do latim, língua oficial do Império. Que se legitimava por intermédio de outros profissionais que acompanhavam os soldados romanos quando conquistavam outros povos, sendo eles: pedagogos e outros funcionários necessários para a consolidação da conquista. $\mathrm{O}$ termo România surgiu a partir de romanus, que formou o advérbio romanice ou "à maneira ou costume romano" (LIMA, 2008, p. 30). Modernamente, o termo România é usado para se referir a toda área ocupada por línguas de origem latina.

A Românica possuiu três períodos: Românica Antiga, Românica Medieval e Românica Moderna.

Para Bassetto (2005), a Românica Antiga era constituída de um conjunto de territórios, que nos primeiros decênios do século II d.C. atingiu sua extensão máxima, com um total de 301 províncias. Essa denominação, de România, no entanto se apoia mais em aspectos políticos que linguísticos.

O período da Românica Medieval ocorreu com a redução da România Antiga, ainda no século II d.C. por causa das invasões dos povos germânicos e eslavos, o que causou a fragmentação primeiramente política e posteriormente linguística. Portanto, com a queda do Império Romano podemos conceituar que a România Medieval correspondia às regiões em que se continua a falar o latim vulgar (BASSETTO, 2005, p. 179-181).

Já o período da Românica Moderna foi o mais longo dentre os três, segundo Bassetto (2005) essa longevidade ocorreu graças a conquista de novos territórios (sobretudo da África pelo portugueses e espanhóis) e por causa das grandes navegações no século XV. Outro fator relevante deste período foi a evolução das Línguas Românicas Modernas (o italiano, o castelhano, o francês e português). Das quais temos nossa matriz - o português de Portugal.

VOL. 14 | N. 1 | JUN. 2017 da palavra ISSN 1415-7950

A partir desse breve histórico, podemos notar o percurso da origem da lín- 
gua portuguesa, do latim clássico, posteriormente pelo latim vulgar até chegar na língua românica moderna - português de Portugal, que através das grandes navegações, viu sua Língua e territórios expandidos. Neste recorte do XVI, que corresponde ao nosso "descobrimento" encontra-se um dos objetos propostos neste estudo: os primeiros relatos dos viajantes sobre a descoberta do território brasileiro e do Rio Grande, atualmente Rio Amazonas, e consequentemente servirá de base para as pontuações posteriores.

\section{O OLHAR ESTRANGEIRO...}

Umas das narrativas mais significativas para o contexto amazônico iniciou-se no século XVI, no ano de 1539, na cidade de Quito, onde saiu a expedição espanhola, com cerca de trezentos e quarenta soldados e mais de quatro mil índios, comandada por Gonzalo Pizarro e posteriormente (ano de 1542) foi encabeçada pelo loco-tenente Francisco de Orellana, que se ofereceu ao comandante Pizarro para baixar pelo grande rio em busca de ajuda para a companhia, que já passara por três anos de dificuldades, no entanto tal ajuda nunca aconteceria, pois o grupo de Orellana não conseguiria voltar devido à forte correnteza, iniciando assim uma aventura de oito meses e $6000 \mathrm{~km}$ de navegação por todo rio Amazonas e pelo Atlântico até a ilha de Margarita ${ }^{4}$.

Tais fatos só puderam ser contados por causa de um frei dominicano chamado Gaspar de Carvajal. As crônicas de viagem de Carvajal relataram várias passagens interessantes sobre a descoberta no extremo norte brasileiro. Mas, para este estudo, faremos um recorte na passagem que trata do topônimo dado por Carvajal ao grande rio, que tem estreita ligação com suas memorias e matrizes europeias.

Hão de saber que eles são súditos e tributários das amazonas, e conhecida a nossa vinda, foram pedir-lhes socorro e vieram dez ou doze. A estas nós as vimos, que andavam combatendo diante de todos os índios como capitãs, e lutavam tão corajosamente que os índios não ousavam mostrar as espáduas, e ao que fugia diante de nós, o matavam a pauladas. Eis a razão porque os índios tanto se defendiam [...] Estas mulheres são muito alvas e altas, com o cabelo muito comprido, entrançado e enrolado na cabeça. São muito membrudas e andam nuas em pelo, tapadas as suas vergonhas, com os seus arcos e flechas nas mãos, fazendo guerra como dez índios. (CARVAJAL, 1941, p. 60).

Ao entrar no espaço amazônico, o cronista busca um referente de sua memória tecida na cultura europeia, desde modo, Carvajal descreve as "amazonas" com o olhar estrangeiro, traçando um imaginário grega do mito das amazonas.

A postura de Carvajal apresenta-se como adônica uma vez que nomeia tudo o que lhe é estranho, assim como Deus propôs a Adão:

Sendo assim, o SENHOR modelou, do solo, todos os animais selvagens e todas as aves do céu e, em seguida, os trouxe à presença do homem para ver como este os chamaria; e o nome que o homem desse a cada ser vivo, esse precisamente seria seu nome. (GENESIS 2:19).

Esses topônimos que Carvajal nomeia podem ser vistos em outras passagens da crônica:
$4 \mathrm{KOCH}$, Ingedore Vilhaça; BENTES, Anna Christina; FIGUEIREDO, Aldrin Moura de. A descoberta do Brasil pela Amazônia: o relato de viagem de Gaspar de Carvajal. IN: BARROS, Daina Luz Pessoa de (org). Os discursos do descobrimento: 500 e mais anos de discursos. São Paulo: Editora da Universidade de São Paulo FAPESP, 2000.

"não tínhamos andado obra de duas léguas, quando vimos entrar à mão direita outro rio mui poderoso e maior. Tão vasta 
era a entrada, que fazia três ilhas, razão pela qual chamamos a esse, Rio da Trindade" (CARVAJAL, 1941, p.46).

"vimos uma boca de outro grande rio, à mão esquerda, que entrava no que navegávamos, e de água negra como tinta, e por isso lhe pusemos o nome de Rio Negro" (CARVAJAL, 1941, p.50).

Essa necessidade de tornar familiar o não familiar está presente na teoria das representações sociais de Moscovici (2011), pois temos a necessidade convencionalizar os objetos, pessoas ou acontecimentos que encontramos.

No entanto, a questão levantada neste estudo seria, que tem a autoridade de nomear as coisas? A resposta mais óbvia seria: quem detinha o poder.

Nesse sentido Foucault (2004) descreve que o que existe não é o poder, mas sim relações de poder, ele não está situado em um lugar específico, mas está distribuído e agindo em toda a sociedade, em todos os lugares e em todas as pessoas. Através de seus mecanismos, o poder atua como uma força coagindo, disciplinando e controlando os indivíduos. Para Foucault, de acordo com as necessidades e com as realidades de cada local, são produzidas novas relações de poder.

Tomemos como exemplo inicialmente a analogia topônima mais primitiva da região amazônica, deparamo-nos com as figuras das Ykamiabas e das Amazonas, presente na literatura informativa do Relatório sobre o novo descobrimento do famoso Rio Grande, descoberto por graça divina, desde a sua nascente até à sua foz, pelo capitão de Orelhana, por Frei Carvajal e os mitos, as narrativas mitologias indígenas. Neste contexto o topônimo que prevaleceu foi o do viajante-colonizador: Amazonas e não o nome indígena Ykamiabas.

Para Moscovici (2011) é impossível classificar sem, ao mesmo tempo, dar nomes. Para o autor o ato de nomear algo, o liberta de um anonimato perturbador e consequentemente "para dotá-lo de uma genealogia e para incluí-lo em um complexo de palavras específicas, para localizá-lo, de fato, na matriz de identidade de nossa cultura". (MOSCOVICI, 2011, p. 66).

Assim, a palavra Amazonas (e seus derivados, como Amazônia) se cristalizaram em nossa cultura, na nossa identidade, fazem parte do nosso imaginário, prevaleceram em nossa bacia semântica ${ }^{5}$, dotada de significados alheios que incorporamos como nosso.

Outro topônimo bastante interessante diz respeito ao nome do Estado do Pará. Segundo Tupiassu (2000) inicialmente, o Estado do Pará tinha o topônimo indí-

5 A "bacia semântica" (Gilbert Durand, 1998), em termos gerais é o conjunto de ideias, significados, expressões de dada sociedade, na qual o indivíduo nasce. Incluo-me entre os que são afetados pela bacia semântica e, se o leitor permitir, o incluo também, pois dela ninguém escapa. Conhecemos o mundo, aprendemos a falar e junto com a língua aprendida adquirimos os significados sobre as coisas. No fundo as palavras são conceitos com os quais tratamos a realidade. gena tupinambá que era Paraná-açu (grifos da autora). Sendo "paraná” igual ao mar, e "açu" entre outros sentidos quer dizer "grande". Posteriormente, o português fez outro batismo as águas do Ver-O-Peso, Feliz Lusitânia, contudo a designação Pará/ grande do homem brasílico permaneceu.

no decorrer de uma surda e invisível batalha linguística, no fim venceu a dicção nativa. O embate foi a surgir um topônimo misto - a linguagem talvez a primeira a miscigenar-se - construída de metade lusa grudada numa metade índia. Nasce o substantivo Grão Pará. (TUPIASSU, 2000, p. 44-45).

Muitos outros exemplos poderiam ser encaixados nesta perspectiva que o poder atravessa e nomeação, mas nos ateremos a mais um, um pouco mais contemporâneo, do final do século XIX e início do século XX, período em que o Estado do Pará, assim como boa parte da Região Norte passa por um período econômico bastante satisfatório: A Belle Époque, era de ouro do látex.

Para tanto, tomemos como ponto de a reflexão sobre um monumento do patrimônio de Belém, o Chafariz das Sereias. 


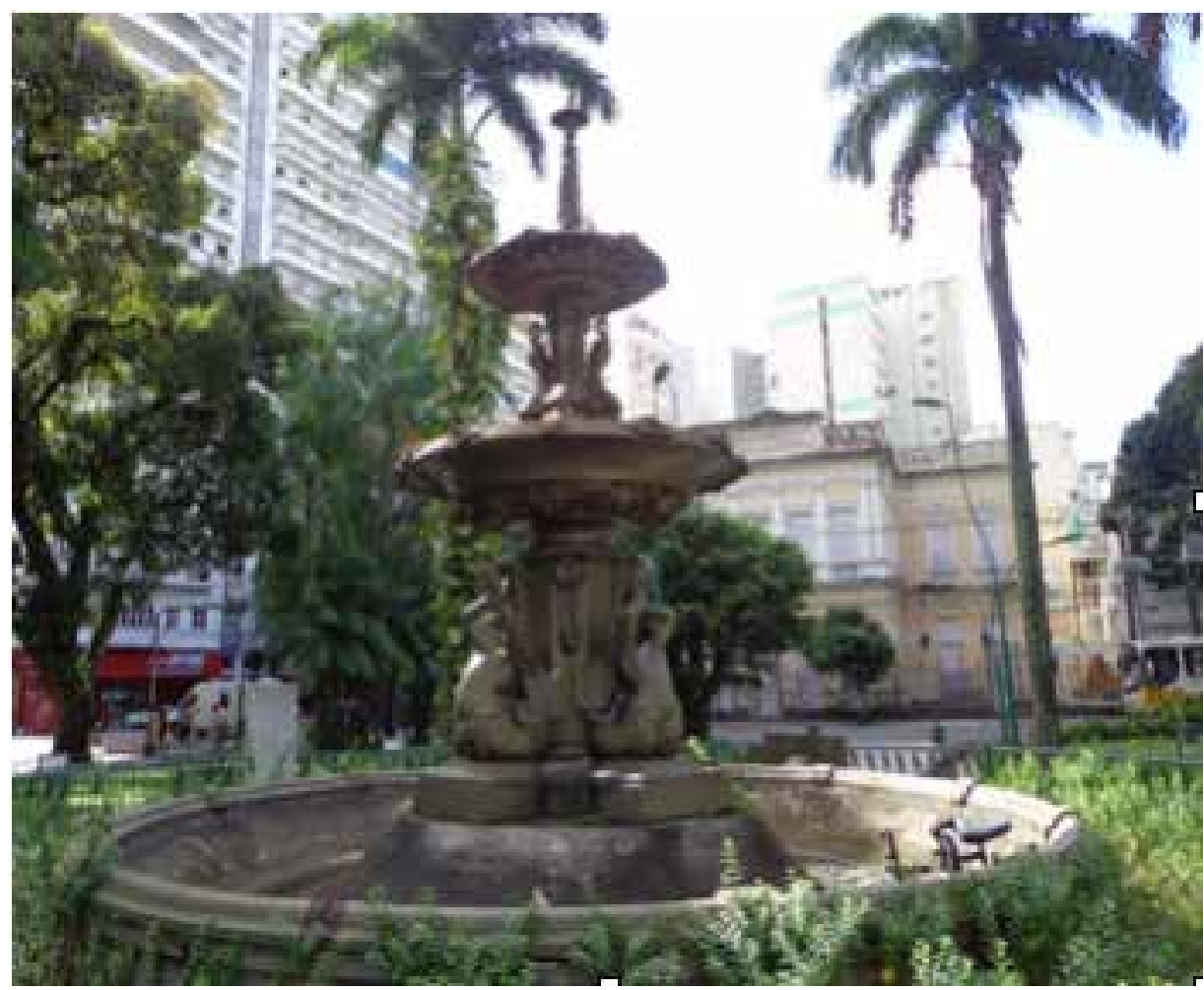

Fonte: site do projeto Transcodificações Urbanas, da Universidade Federal do Pará

Para analisarmos a imagem do Chafariz das Sereias, trabalharemos com os conceitos de Barthes (1990) sobre sentidos que a imagem possui, sendo eles: o nível informativo (comunicação); nível simbólico (significação) e o nível obtuso.

No nível informativo, ou seja, o sentido posto, denotado, temos um Chafariz no formato de Sereias em uma praça, na cidade de Belém do Pará, que teve sua estrutura concluída em $1904^{6}$.

O sentido nível simbólico, está no campo da conotação, da comunicação, nele podemos aludir que o monumento representa um ciclo de riqueza da burguesia do Estado do Pará, onde os modelos de civilidade e embelezamento eram inspirados na Europa, trata-se ainda de um monumento em estilo Art Nouveau ${ }^{7}$ importado da Europa, aos moldes de Le France ${ }^{8}$, que até hoje podo ser observados nas arquiteturas dos prédios também.

Já o nível obtuso, que para Barthes (1990) é velado, insistente e fugidio, liso e esquivo, analisaremos a partir da escolha do nome "Chafariz das Sereias", na ideologia que ele representa. Além de ser um representante do boom da borracha, ele está impregnado de marcas de violência contra a cultura amazônica. Para Machado (2003) o grupo autor do Nome tem autoridade sobre seu portador. E, se a autoridade leva à autoridade, esta, por sua vez, coincide com a propriedade. O Nome marca também um aspecto da subjetividade ou da posição social daquele que nomeia, e que é significado pelo Nome que escolhe. Portanto, o Nome é sempre significativo. E sempre uma forma de classificação. Então, fica a indagação: quem neste dado momento histórico nomeia?

Diferentemente dos dois primeiros exemplos (nomes Amazonas/Ykamiabas e do Pará), não é o viajante, nem o colonizador português e sim o próprio nortista, mas não qualquer nortista, é a elite paraense, que subjuga sua identidade amazônica e enaltece o estilo europeu, prefere as "sereias" as "yaras". Esse exemplo do chafariz pode ser estendido a todo patrimônio arquitetônico, no chamado processo de urbanização e embelezamento ${ }^{9}$ da cidade naquele período.

A relação que fica implícita no ato de autoridade de nomeação das coisas, lugares e objetos, remetem as relações de poder, entendidas sobretudo em Foucault VOL. 14 | N.1 | JUN. 2017

6 Projeto Transcodificações Urbanas, da Universidade Federal do Pará, disponível em: http:// www.monumentosdebelem. ufpa.br/transcodificacao/index. $\mathrm{php} /$ monumento/sereias.

7 Art Noveau ou Arte Nova foi um movimento artístico que surgiu no final do século XIX na Bélgica, fora do contexto em que normalmente surgem as vanguardas artísticas. Vigorou entre 1880 e 1920 , aproximadamente. No Brasil, observam-se leituras e apropriações de aspectos do estilo Art Nouveau na arquitetura e na pintura decorativa. Em sintonia com o boom do ciclo da borracha, entre 1850/1910, as cidades de Belém e Manaus tem, incorporados à sua arquitetura, vários elementos Art Nouveau.

8 SARGES, Maria de Nazaré. Belém: Riquezas Produzidas a Belle-Époque (1870 - 1912). Belém: Paka-Tatu, 2000.

9 Idem, 2000 
(2004) onde o que existe não é o poder, mas sim relações de poder, ele não está situado em um lugar específico, mas está distribuído e agindo em toda a sociedade, em todos os lugares e em todas as pessoas. Através de seus mecanismos, o poder atua como uma força coagindo, disciplinando e controlando os indivíduos. Para Foucault, de acordo com as necessidades e com as realidades de cada local, são produzidas novas relações de poder.

Sobre está ótica, podemos entender que os poderes que atravessaram e atravessam nossa cultura não estão nas pessoas, estão nas relações, que se materializam ora pelos olhos dos viajantes, ora pelo colonizador europeu ou até mesmo pela própria elite nortista.

\section{ALGUMAS CONSIDERAÇÕES...}

Neste estudo, percebemos que a região Amazônica é um território amplo, que precisa ser melhor explorado em vários aspectos. É preciso reconhecer ainda as diversidades, práticas e manifestações culturais que não podem ser homogeneizadoras. Pois, independente da denominação das nomenclaturas utilizadas para retratar o sujeito e os topônimos da Amazônia, devemos buscar, em primeiro lugar, o reconhecimento da importância de participação dessas sociedades no processo de formação política e identitária local, seja ela indígena, cabocla, ribeirinha, africana ou europeia.

Assim, falar dos povos da Amazônia requer um (re)conhecimento da grande diversidade ambiental e social da região, neste estudo tratamos de uma Amazônia paraense de identidades plurais, vários Parás dentro de um Pará. Diferenciada em suas matrizes geracionais, marcada por dinamismos, sincretismos e relações de poder.

Portanto, ao concluir este breve estudo, deixaremos algumas interrogativas entendidas em Maldonato (2005) e façamos as devidas reflexões a partir de das considerações de Maldonato (2005, p. 489) quando o autor afirma que é possível pensar em uma relação consigo próprio que não seja uma volta a si, uma repatriação em si, um render-se à ilusão da identidade? Como vou encetar uma relação com o outro, estrangeiro, que chega repentinamente, como um evento inesperado; ao outro, estrangeiro, que bate à minha porta e perturba a minha paz doméstica? É possível falar deste encontro recorrendo às retóricas da hospitalidade? Enfim, os direitos do estrangeiro podem prevalecer sobre os direitos do anfitrião? Deixamos esta reflexão.

\section{REFERÊNCIAS:}

BARTHES, Roland. O óbvio e o obtuso: ensaios críticos III. Rio de Janeiro: Nova Fronteira , 1990.

BASSETTO, Bruno Fregni. Elementos da Filologia Românica: história externa das línguas. $2^{\mathrm{a}}$ ed. São Paulo: Editora da Universidade de São Paulo, 2005.

CARVAJAL, Gaspar de. Descobrimento do Rio de Orellana. In: Descobrimentos do Rio das Amazonas. Tradução: C. de Melo-Leitão. São Paulo: Companhia Editora Nacional, 1941.

CARVALHAL, Tania Franco. Literatura comparada. São Paulo, Ática, 1994. Série Princípios.

DURAND, Gilbert. O imaginário: Ensaio acerca das ciências e da filosofia. São Paulo: Difel, 1999.

FOUCAULT, M. Microfisica do poder. 23. ed. São Paulo: Graal, 2004. 
$\mathrm{KOCH}$, Ingedore Vilhaça; BENTES, Anna Christina; FIGUEIREDO, Aldrin Moura de. A descoberta do Brasil pela Amazônia: o relato de viagem de Gaspar de Carvajal. IN:

BARROS, Daina Luz Pessoa de (org). Os discursos do descobrimento: 500 e mais anos de discursos. São Paulo: Editora da Universidade de São Paulo - FAPESP, 2000 .

LIMA, Joaquim Maia de. Filologia Românica. Belém: EDUFPA, 2008.

MACHADO, Ana Maria. Recado do Nome: Leitura de Guimarães à luz do Nome de seus personagens. $3^{\mathrm{a}}$ ed. Rio de Janeiro: Nova Fronteira, 2003.

MALDONATO, Mauro. Arquipélago identidade: o declínio do sujeito autocêntrico e o nascimento do eu múltiplo. Revista Latinoamericana de Psicologia Fundamental. 2005 , p. $480-496$

MELO, Regina. Ycamiabas: filhas da Lua, Mulheres da Terra. Manaus: Editora Travessia/Petrobrás, 2004.

MOSCOVICI, Serge. Representações Sociais: investigações em psicologia social. Editado em inglês por DUVEEN, Gerard; traduzido do inglês por GUARESCHI, Pedrinho A. $8^{\mathrm{a}}$ ed. Petrópolis. Editora Vozes, 2011.

SARGES, Maria de Nazaré. Belém: Riquezas Produzidas a Belle-Époque (1870 1912). Belém: Paka-Tatu, 2000.

TUPIASSU, Amarílis. Riso e Pranto nos Mares do Descobrimento ou Ensaios sobre História e Poesia. Belém: UNAMA, 2000. 